\title{
A new technique of bladder neck reconstruction during radical prostatectomy in patients with prostate cancer
}

\author{
Yuri Tolkach ${ }^{1,2}$, Konstantin Godin ${ }^{3}$, Sergey Petrov ${ }^{2}$, Sonny Schelin ${ }^{4}$, Florian Imkamp ${ }^{1}$ \\ ${ }^{1}$ Hannover Medical School, Urology and Urologic Oncology Clinic, 30625 Hannover, Deutschland; \\ 2 Military Medical Academy, Urology Clinic, 194044 Saint-Petersburg, Russia; ${ }^{3}$ Südharz Klinikum \\ Nordhausen, Urology Clinic, 99734 Nordhausen, Deutschland; ${ }^{4}$ Kalmar County Hospital, 39231 Kalmar, \\ Sweden
}

\section{ABSTRACT}

Purpose: To evaluate continence after radical prostatectomy in prostate cancer patients, in whom a new method of the bladder neck reconstruction (BNR) using deep dorsal stitch was implemented (deep single stitch through all bladder layers directly dorsal to the bladder opening after "tennis racket" reconstruction) and to provide justification for its use by means of anatomical study in cadavers.

Material and Methods: Open radical retropubic prostatectomy was performed in 84 patients: 39 patients with a new BNR method used to improve continence and control group of 45 patients with standard "tennis racket" BNR. Median follow-up was 14 months in control group and 12 months in study group. Continence recovery was accessed early postoperatively and every 3 months thereafter. Anatomical study was performed on 2 male fresh cadavers reproducing two different BNR techniques to clarify any underlying continence related mechanisms.

Results: Patients with new BNR achieved full continence significantly faster $(p=0.041)$, but the continence rates after 12 months were similar between groups. The severity of incontinence up to month 9 was significantly reduced in BNR group. The anastomotic stricture rate was not affected. Applying new BNR to the cadaver model revealed effects on early continence, namely presence of proximal passive closure mechanism in area of bladder neck.

Conclusions: Continence in patients with the new BNR method using deep dorsal stitch recovered significantly faster. Moreover, a reduced grade of residual incontinence was documented. The effect was non-significant at month 12 of follow-up, meaning that only early effect was present.

\section{ARTICLE INFO}

Key words:

Prostatic Neoplasms;

Prostatectomy; Urinary Bladder;

Urinary Incontinence

Int Braz J Urol. 2015; 41: 455-65

Submitted for publication: July 10, 2014

Accepted after revision: September 18, 2014

\section{INTRODUCTION}

Prostate cancer is one of the most common cancers in men. It has the highest incidence among other cancers and is in third place in the structure of cancer related male mortality in Europe (1). Many patients are in need of radical treatment every year. The most common types of applied treatments with curative intent are radical prostatectomy and radiation therapy with the surgical treatment being most common in every day practice (2).

Among the main clinical problems related to the surgical treatment of prostate cancer are early and late complications which arise shortly after operation, namely urinary incontinence and erectile dysfunction, which affect more than 50\% patients 
$(3,4)$, negatively affecting the quality of life in a prolonged and sometimes irreversible manner. The post-operative incontinence can last more than 1 year after the operation in up to $10 \%$ of the patients $(4,5)$, significantly impairing the social functioning in this mostly very active contingent of patients.

The imperfect nature of the radical prostatectomy with regard to the urinary continence was object for intense investigations, mainly with an urgent task to improve the operational technique in order to preserve continence in the majority of patients $(6,7)$. One group of technical methods, which could potentially improve continence after radical prostatectomy is bladder neck reconstruction, that were investigated in small mainly underpowered studies with an overall tendency to improve the continence early after operation with no differences in general after one year. (8-15).

The aim of this investigation was to evaluate the functional outcomes of radical prostatectomy in terms of urinary continence in patients with prostate cancer, in whom a new method of bladder neck reconstruction (BNR) with a deep dorsal stitch was applied, and also to find the potential underlying mechanisms for the efficacy of the BNR using an anatomic model.

\section{MATERIALS AND METHODS}

This is a controlled clinical study with prospectively collected data performed in 84 consecutive male patients. All patients underwent open radical retropubic prostatectomy due to the presence of histologically confirmed localized prostate cancer of all clinical risk groups (cT1-cT3NOM0, any PSA, any preoperative Gleason score). In 39 patients a new method of bladder neck reconstruction using a deep dorsal stitch was used, aimed to improve the functional outcomes (urinary continence) after radical prostatectomy. Another 45 patients, in whom a standard reconstruction using "tennis racket" was implemented, were used as a control group. All patients were operated on in the period of 20082010 years in a high-volume uro-oncological center (Urology Clinic of Military Medical Academy, Saint-Petersburg, Russia) by a single surgeon (S.P.) with a background of approximately 400 open radical prostatectomies and 10 years of experience with this operation. The two patient groups included in this study represented two consecutive series (operations on patients in control group were performed earlier than in the new BNR group). Only those patients in whom the nerve bundles were not preserved were included into analysis for the conceptual isolation of the new BNR method. Formally, part of the patients included in the study had the indications for nerve sparing, but this technique was not applied as it was only recently introduced in clinical practice and was not performed at that moment in all patients.

Preoperative staging was performed according to the current European Association of Urology guidelines. All patients included in the study were continent prior to operation.

\section{Description of the standard method of the BNR}

After removal of the prostate with the retrograde dissection technique (release of the apex, transection of urethra, retrograde ligation of vascular pedicles, dissection of prostate off the bladder) eversion of the bladder mucosa was performed and bladder neck was narrowed with the use of running Vycril $2 / 0$ suture from the dorsal edge of the bladder neck opening resulting from prostate removal (so-called "tennis racket" reconstruction, Figure-1, A-D). Additional single stitch (Vycril 2/0) was used to approximate the dorsal part of the rhabdosphyncter and the remaining portion of the vesico-prostatic muscle dorsal to the bladder neck (Rocco stitch (16). Anastomosis was created using 4 to 7 single sutures of Vycril 3/0 (median 5 stitches).

Description of the new method of the BNR (BNR using deep dorsal stitch)

After removal of the prostate a standard "tennis racket" tapering was made as described above. Then a BNR using deep dorsal stitch was performed (Figure-1, A-F; Figure-2). A deep stitch was applied at the posterior semi-circumference of the previously created "tennis racket" with a polyfilament absorbable material (Vycril 0) through all layers of the bladder wall over the previous narrowing suture. During the tightening of this stitch, a bougie $28 \mathrm{Ch}$ was introduced into the bladder cavity to prevent a possible contraction of the aperture. 
Figure 1 - Consecutive steps of bladder neck reconstruction using the standard and deep stitch techniques: A) Direct view of bladder neck after removal of prostate specimen; B) Mucosa eversion; C, D) 'tennis racquet' reconstruction of the bladder neck; E) Placing of the deep stitch dorsally to the bladder neck orifice through all layers of the bladder wall; F) The final view of bladder neck after reconstruction.

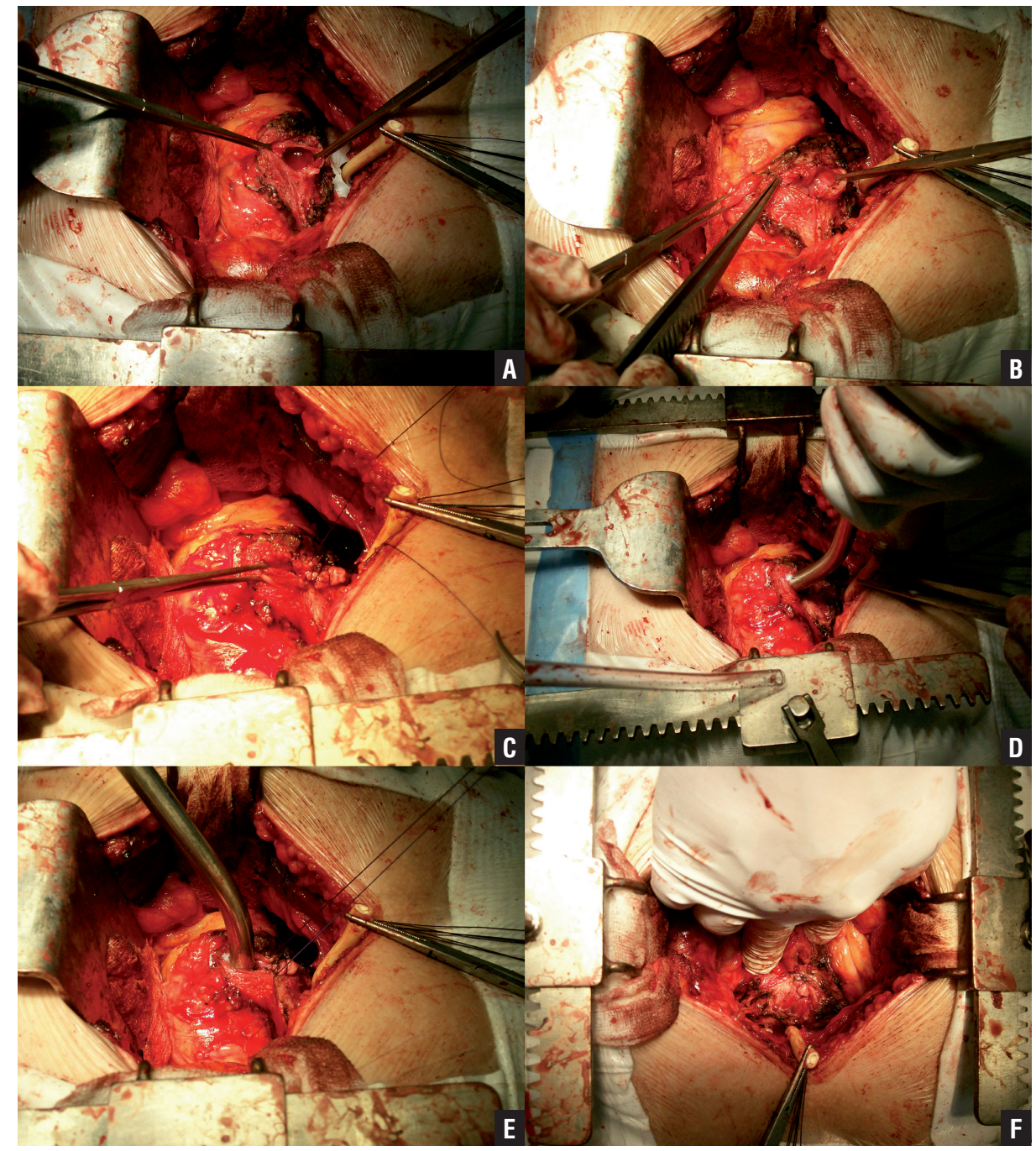

Images $\mathrm{A}-\mathrm{D}$ are the steps of the standard technique, $\mathrm{A}-\mathrm{F}$ - the steps of the technique under investigation.

After tightening the stitch the bougie was removed and anastomosis was finished equally as described for the standard method.

With this deep dorsal stitch the opening of the bladder neck was compressed by the surrounding tissues but without reducing the diameter of the orifice (Figures 1 and 2).

This technique of BNR was suggested by Sonny Schelin (Kalmar County Hospital, Kalmar, Sweden).

\section{Postoperative follow-up}

The continence status was evaluated at 6 control time points-within 1 week after catheter removal and at 1, 3, 6, 9 and 12 months after operation.

The evaluated parameters were:

1. Question: Is full continence achieved?

2. Number of the incontinence pads used per day.

3. Assessment using questionnaire ICIQ-UI SF (International Consultation on 
Figure 2 - Schematic representation of the steps of the bladder neck reconstruction using deep stitch technique: A) Bladder neck view after formation of classic 'tennis racket'; B) Deep stitch is made dorsally to bladder orifice through all layers of the bladder wall; C) Tightening of the suture results in the tissue shift, which represents a formation of proximal passive closure mechanism (compression of the bladder neck orifice with surrounding tissues without reducing the diameter). A bougie ( ${ }^{*}$ ) should be introduced into the bladder neck to prevent substantial shrinkage of the tissues during the tightening of the suture.

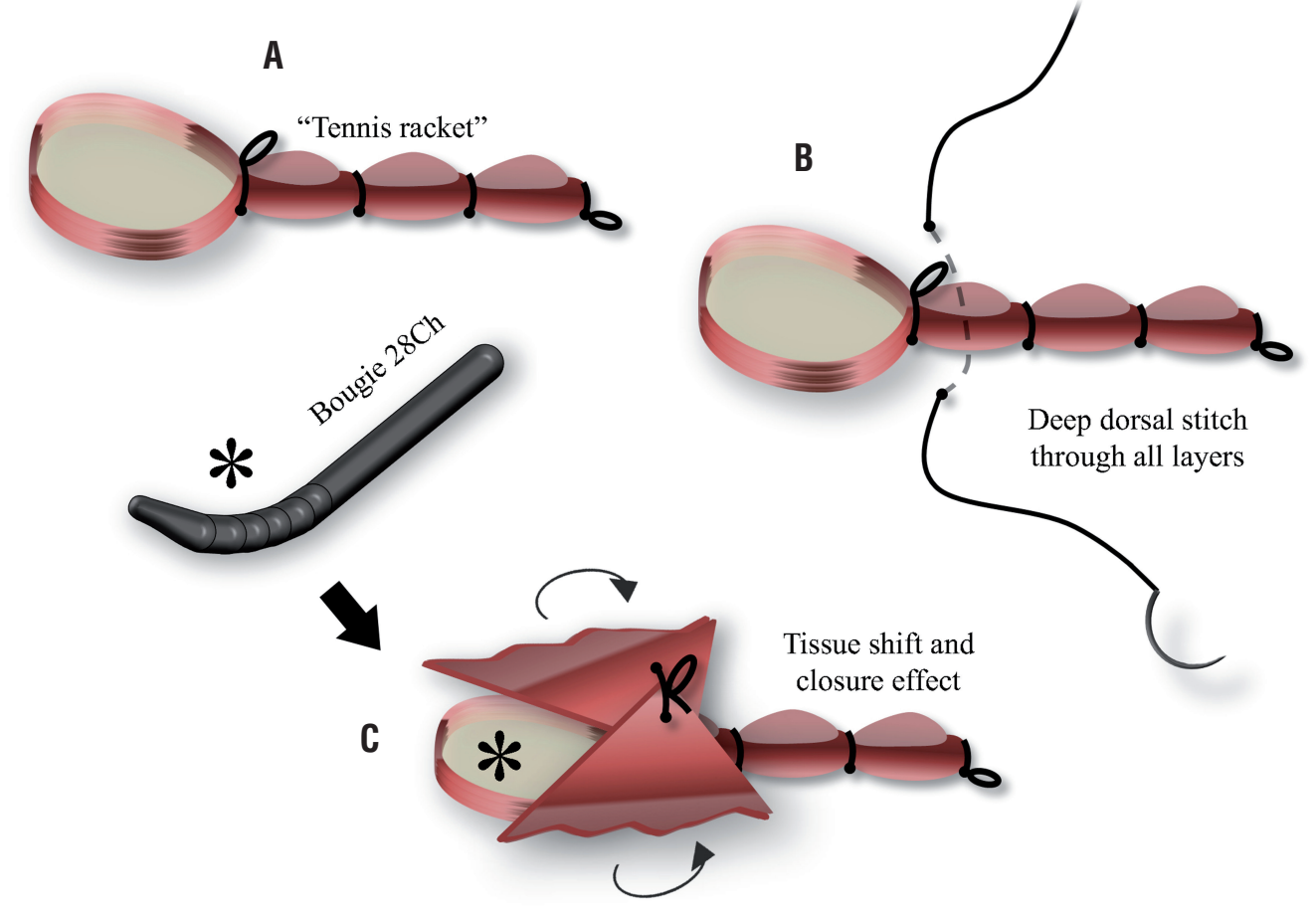

Incontinence Questionnaire Urinary Incontinence Short Form) in a version, validated for Russian language.

Full continence was strictly defined as full absence of urine leakage. All patients were controlled for residual volume (ultrasound), decrease in the micturition velocity (uroflowmetry, Qmax), and for the newly arising lower urinary tract symptoms during follow-up.

\section{Ethical issues}

Institutional review board and ethical committee of the Military Medical Academy (Saint-Petersburg, Russia) approved this study.

\section{Anatomical study}

Anatomical study was performed on two fresh male cadavers with documented reason of death demonstrating no link to the lower urinary tract, which were used to reproduce all steps of radical pros- tatectomy using both BNR methods under investigation. The intention was to identify anatomical factors, which could pre-determine the efficacy of the BNR with regard to the urinary continence after radical prostatectomy. Anatomical study was covered by the permission of the ethic commission.

\section{Statistics}

Statistical analysis was performed using the STATISTICA 8.0 software (StatSoft, Tulsa, USA). Life tables and Kaplan-Meyer analysis were used to compare continence recovery in patients with standard technique and deep stitch technique under investigation.

\section{RESULTS}

Median follow-up for the patients after radical prostatectomy was 14 months in the standard BNR group and 12 months in the group of 
the patients with the new reconstruction technique using deep dorsal stitch.

Preoperative and perioperative clinical parameters are shown in Tables 1 and 2. The patient groups had no significant differences in age, prostate volume, total PSA level, biopsy results, clinical stage of prostate cancer (cT-stage), estimated blood loss and duration of pelvic drainage.

Operation time showed statistically significant differences between the groups with longer duration in the control group $(\mathrm{p}=0.044)$. This fact was probably related to the consecutive nature of the patients.

The duration of catheterization tended to be longer in the control group. This was related to the change in institutional guidelines during the period of study regarding the initial necessity of the extended catheterization time in all patients after prostatectomy.
The results of the follow-up regarding urinary continence are summarized in Table-3. A higher percent of patients submitted to the new method of BNR achieved full continence early after catheter removal, at months 1 and 3, with a clear positive trend at month 6 , when compared to the standard BNR. Starting from the month 9 this difference was no more observable. The analysis of time to full continence was also carried out using life tables and Kaplan-Meier curves (Figure-3). The Kaplan-Meier curves data for full continence achievement were analyzed using Gehan-Wilcoxon criteria, which showed a statistically significant difference in favor of the new BNR technique $(p=0.041)$. In conclusion, the new method of BNR led to achievement of full continence faster, but the continence rates by the end of the study follow-up (12 months) were similar between the groups. Two patients in study group

Table 1 - Preoperative characteristics of the patients (by groups).

\begin{tabular}{|c|c|c|c|}
\hline Parameter & $\begin{array}{l}\text { Study Group } \\
\quad(\mathrm{n}=39) \\
\operatorname{Me}\left(Q_{25} ; Q_{75}\right)\end{array}$ & $\begin{array}{l}\text { Control Group } \\
\quad(n=45) \\
\operatorname{Me}\left(Q_{25} ; Q_{75}\right)\end{array}$ & p-level \\
\hline Age, years & $60.1 \pm 4.7^{1}$ & $60.3 \pm 6.5^{1}$ & 0.851 \\
\hline Prostate volume (Ultrasound), $\mathrm{mL}$ & $31(20.9 ; 36.3)$ & $34(22 ; 48)$ & 0.202 \\
\hline Total PSA, ng/mL & $7.5(5.3 ; 11.2)$ & $9.4(6.1 ; 15.0)$ & 0.117 \\
\hline \multicolumn{4}{|c|}{ Division of patients based on Gleason sum, pts. (\%) } \\
\hline $2-4$ & $3(7.7)$ & $7(15.6)$ & \multirow[t]{3}{*}{0.353} \\
\hline $5-7$ & $32(82.1)$ & $36(80.0)$ & \\
\hline $8-10$ & $4(10.2)$ & $2(4.4)$ & \\
\hline \multicolumn{4}{|c|}{ Division of patients based on clinical stage, pts. (\%) } \\
\hline cT1c & $22(56.4)$ & $21(46.7)$ & \multirow[t]{6}{*}{0.682} \\
\hline cT2a & $2(5.1)$ & $3(6.7)$ & \\
\hline cT2b & $5(12.8)$ & $3(6.7)$ & \\
\hline cT2c & $5(12.8)$ & $7(15.6)$ & \\
\hline сТ3а & $3(7.7)$ & $8(17.8)$ & \\
\hline cT3b & $2(5.1)$ & $3(6.7)$ & \\
\hline
\end{tabular}

${ }^{1}$ Mean \pm Standard deviation 
Table 2 - Perioperative characteristics of the patients (by groups).

\begin{tabular}{|c|c|c|c|}
\hline Parameter & $\begin{array}{c}\text { Study Group } \\
\quad(n=39) \\
\text { Me }(Q 25 ; Q 75)\end{array}$ & $\begin{array}{c}\text { Control Group } \\
(n=45) \\
\text { Me }(Q 25 ; Q 75)\end{array}$ & p-level \\
\hline Operation time, min & $180(150 ; 205)$ & $200(180 ; 250)$ & 0.044 \\
\hline Estimated blood loss, mL & $300(200 ; 500)$ & $300(200 ; 500)$ & 0.635 \\
\hline \multicolumn{4}{|l|}{ Type of suture material for anastomosis } \\
\hline pts. $(\%)$ & $36(92.3)$ & $41(91.1)$ & \\
\hline Vycril 3/0 & 0 & $1(2.2)$ & 0.074 \\
\hline Vycril 2/0 & $3(7.7)$ & 0 & \\
\hline $\begin{array}{l}\text { Monocryl 3/0 } \\
\text { PDS } 2 / 0\end{array}$ & 0 & $3(6.7)$ & \\
\hline Duration of catheterization, days & $12(10 ; 13)$ & $13(12 ; 15)$ & 0.038 \\
\hline $\begin{array}{l}\text { Urinary extravasation }{ }^{1} \text { according to cystography, pts. } \\
(\%)\end{array}$ & $8(20.5)$ & $12(26.6)$ & 0.188 \\
\hline Duration of pelvic drainage, days & $6(4 ; 8)$ & $6(4 ; 7)$ & 0.649 \\
\hline
\end{tabular}

${ }^{1}$ mostly very small extravasation pattern not warranting prolonged catheterization.

Table 3 - Continence status of the patients and incontinence severity during the follow-up period (by groups).

\begin{tabular}{lccc}
\hline Timepoint/Parameter & $\begin{array}{c}\text { Study Group } \\
(\mathrm{n}=39)\end{array}$ & $\begin{array}{c}\text { Control Group } \\
(\mathrm{n}=45)\end{array}$ & p-level \\
\hline Patients: incontinent/total on follow-up (percent of fully continent patients) & & \\
1 -7 days after catheter removal & $28 / 39(28.2 \%)$ & $38 / 45(15.6 \%)$ & 0.159 \\
1 month after operation (OP) & $22 / 39(43.6 \%)$ & $33 / 45(26.7 \%)$ & 0.01 \\
3 months after OP & $14 / 35(60.0 \%)$ & $28 / 45(37.8 \%)$ & 0.02 \\
6 months after OP & $7 / 32(78.1 \%)$ & $16 / 45(64.4 \%)$ & 0.175 \\
9 months after OP & $5 / 32(84.4 \%)$ & $8 / 45(82.2 \%)$ & 0.77 \\
12 months after OP & $2 / 32(93.8 \%)$ & $4 / 45(91.1 \%)$ & 0.670 \\
ICIQ-UI SF, points (Me $\left(\mathbf{Q}_{25} ; \mathbf{Q}_{75}\right)$ & & & $<0.001$ \\
$1-7$ days after catheter removal & $10(9 ; 13.5)$ & $15(13 ; 17)$ & $<0.001$ \\
1 month after OP & $10(9 ; 13)$ & $15(13 ; 16)$ & $<0.001$ \\
3 months after OP & $9(8 ; 10)$ & $14(12 ; 15)$ & 0.077 \\
6 months after OP & $9(9 ; 13)$ & $12(10 ; 13.5)$ & 0.048 \\
9 months after OP & $9(9 ; 10)$ & $12.5([10 ; 13.5)$ & 0.817 \\
12 months after OP & $10.5(7 ; 14)$ & $13(10.5 ; 13.5)$ & \\
Pads per day (Me ( $\left.\mathbf{Q}_{25} ; \mathbf{Q}_{75}\right)$ & & & 0.001 \\
$1-7$ days after catheter removal & $1(1 ; 2)$ & $2(2 ; 3)$ & $<0.001$ \\
1 month after OP & $1(1 ; 2)$ & $2(2 ; 2)$ & 0.003 \\
3 months after OP & $1(1 ; 1)$ & $2(1.5 ; 2)$ & 0.033 \\
6 months after OP & $1(1 ; 1)$ & $2(1 ; 2)$ & 0.558 \\
9 months after OP & $1(1 ; 1)$ & $1(1 ; 2)$ & 0.345 \\
12 months after OP & $1(1 ; 1)$ & $1.5(1 ; 2.5)$ & \\
\hline
\end{tabular}

${ }^{1}$ part of the patients by this time point was excluded from the analysis without achieving continence because of short follow-up period. 
Figure 3 - Kaplan-Meyers curves for the continence restoration in the studied patient groups. Group 1) New method of BNR using deep dorsal stitch, Group 2) Standard BNR using "tennis racket" technique.

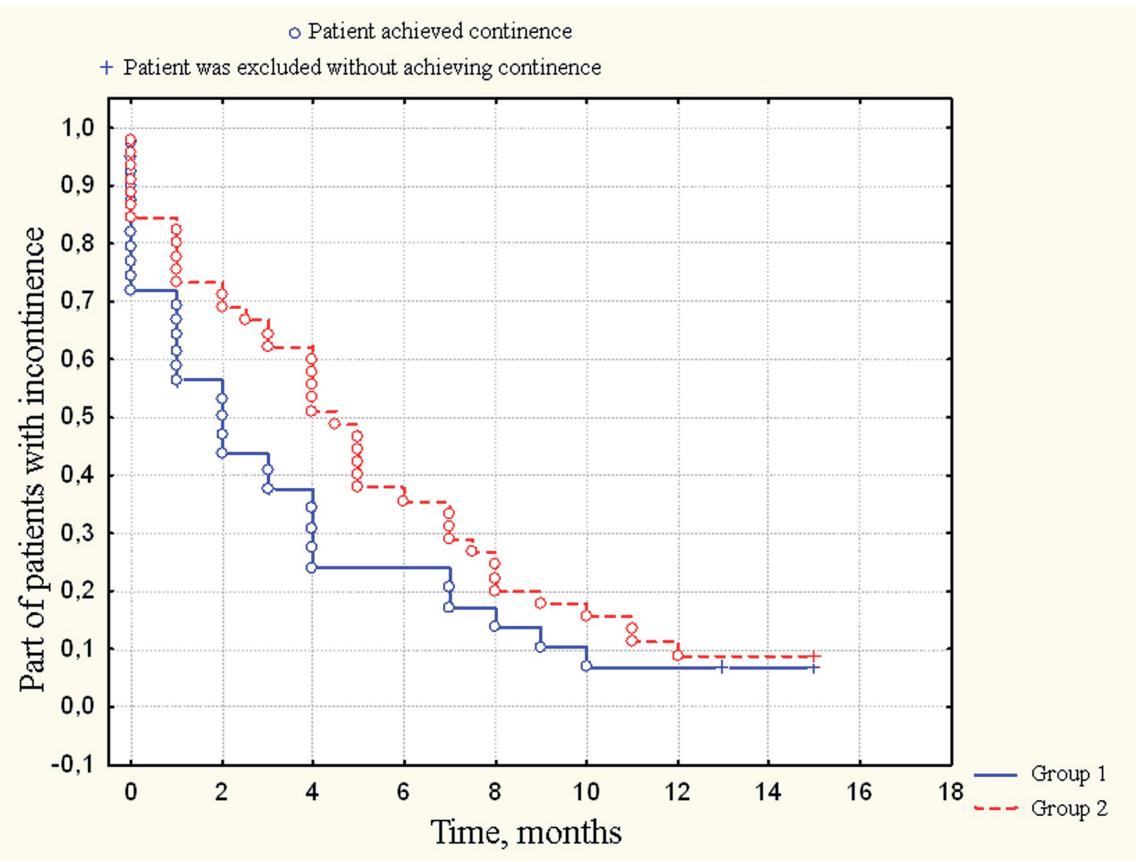

and 4 in control group didn't achieve full continence by the end of the first year ( $p>0.05)$.

The analysis shows that the severity of the incontinence in patients who were still incontinent (determined by the ICIQ-UI SF questionnaire in a week after catheter removal, at 1,3 , 6, 9 and 12 months) was significantly different in both groups favoring the study group (Table-3). But the difference was no longer significant by month 12. The similar trend was observed for the pad usage in favor of the study group with the new method of BNR.

The rate of BNR complication (stricture of the vesico-urethral anastomosis) was also analyzed. The stricture was diagnosed in $7.7 \%$ and $8.8 \%$ of the patients in the study and control groups respectively by the end of the follow-up period ( $p>0.05$ ). All cases except one required urethral dilation for the stricture. There were no cases of acute or chronic urinary retention or urine flow deterioration except on the patients with stricture of vesico-urethral anastomoses in both groups.
As an extension of our study we have performed an anatomic model of the new and standard techniques of the bladder neck reconstruction using fresh cadaver material (Figure-4). The final outside-inside views of the bladder neck using deep dorsal stitch and standard BNR methods are presented in Figure-4. The principal difference between these two methods of bladder neck reconstruction was that bladder neck orifice after reconstruction was wide and open in "tennis racket" BNR and closed and compressed by the surrounding tissues in case of the deep stitch new technique. This compression did not cause shrinkage of the diameter of the bladder neck opening, and therefore did not predispose to bladder neck stricture. We concluded that, placing a deep stitch dorsally to the bladder neck led to a formation of a proximal passive closure mechanism, which enabled to control small increases in intra-abdominal pressure preventing urine leaks during non-intense physical activity (changing body position, cough etc.). This concept was proven, when the bladder after BNR 
Figure 4 - Anatomical justification for the efficacy of the new bladder neck reconstruction technique. A view into the bladder cavity: A and B) Wide open bladder neck orifice by the standard reconstruction ('tennis racquet'); C and D) The orifice is closed by the surrounding tissues, in fact is situated within the tissues (passive proximal closure mechanism due to compression by the surrounding tissues without any changes in the diameter of the bladder neck orifice).

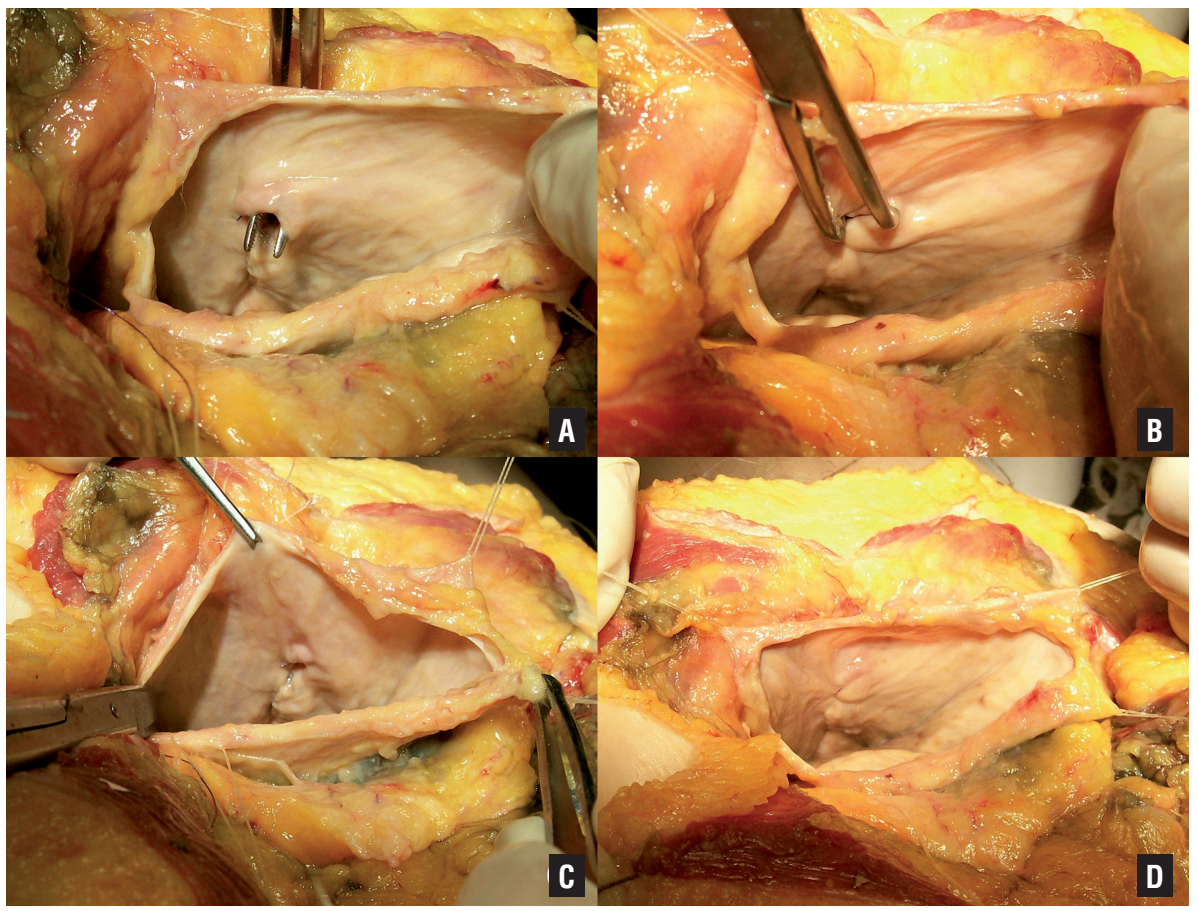

and before finalizing anastomosis was filled with fluid and a gradually rising pressure was applied to the bladder wall, simulating increases in intra-abdominal pressure. It was obvious that when little pressure was applied there was no leakage with the new technique, while the BNR using the "tennis racket" tended to leak independently of the pressure magnitude.

\section{DISCUSSION}

The method of BNR using deep dorsal stitch that was investigated in our study could be considered as one of the bladder neck reconstruction techniques used in prostatectomy. Among these techniques the tubularization of the bladder neck using the circular flap, bladder neck invagination, bladder neck plication and intussusception (8-15) are commonly used in clinical practice for decades. The efficacy of these techniques was not confirmed in large prospective studies, though their use is rational from the anatomical point of view. Published long term outcomes are limited. Few studies mentioned the increased risk of complications inherent to more aggressive techniques of bladder neck reconstructions tubularization (13). The method of BNR using a deep dorsal stitch is technically and conceptually close to the intussusception technique of Walsh P. et al. (10) and to the plication technique of Lee et al. (11). Nevertheless, direct comparison of these methods to the deep dorsal stitch method is hard to do, while the anatomical justification of the potential efficacy is lacking.

In our study we have used the anatomic model in cadavers to elucidate the underlying anatomical mechanisms of the deep dorsal stitch BNR application, which according to our study led to better early continence control after radical prostatectomy. The results provide a possible explanation for the early restoration of continence (Figure-4). The presence of so called proximal passive closure mechanism in the area of the bladder neck opening was implemented through the 
compression by surrounding tissues. On the contrary, a wide opening of the bladder neck could be seen in patients submitted to standard technique of BNR, free for pressure transmission from the bladder cavity to the urethra.

Deep stitching through all layers dorsally to the opening of the bladder neck didn't change the diameter of the outflow orifice. The absence of shrinkage was prevented by the insertion of the bougie in the bladder cavity before tightening the stitch. Nevertheless, this technique could raise some concerns regarding the increased risk of anastomosis stricture. However this was not observed in our patients. In the described limited follow-up period the rate of anastomosis stricture in the group that received the new BNR technique was low (7.7\%) and comparable to the standard group rate $(8.8 \%)$ and to the rates (2.1-10.9\%) reported in the contemporary literature $(17,18)$. Moreover, it could be stated that the highest risk for the development of anastomotic stricture is present in the first postoperative year $(17,19)$, which is within our follow-up period for the majority of the patients.

According to the opinion of many urologists, the bladder neck zone after prostatectomy doesn't play a significant role in urinary continence $(7-20,21)$. The proponents of this theory suggest that achievement of continence is a question of time, which is necessary for the distal sphincter complex to take over the function of the proximal one. We believe that early after operation (up to 6 months) a passive proximal closure mechanism could be beneficial for the continence restoration and could compensate at least partially the changes in abdominal pressure related to the activity of the patient, responsible for post-operative incontinence. Later on, structural and functional adjustments of the distal sphincter are a much more important issue in all patients, which could account for the absence of significant difference in the continence rates between the investigated groups by the month 12 of the follow-up.

In our study we have used ICIQ-UI SF questionnaire for the evaluation of the patients, which is a reliable tool to measure the continence status and a subjective reaction to incontinence (22-24). The results of the analysis show that the differences in the ICIQ-UI SF scores were significant between the groups in the first 6 months of the follow-up. Later the difference is non-significant, which probably relates to the fact that the number of patients still being incontinent is reduced and by the end of follow-up in both groups only the patients who had a severe incontinence from the start remained incontinent. This was probably due to the initially low functional reserve of the distal sphincter complex.

The obvious limitation of this study is the absence of nerve sparing in our patients, which is nowadays a standard part of the radical prostatectomy, whenever possible. However, it can be stated that the relationship of nerve sparing and continence-related functional results is uncertain and the effect of one side nerve preservation is also vague. Other limitations of the study are the relatively small number of patients in both groups, the consecutive nature of the cases and non-randomized design. Our study was carried out using the controlled before-and-after intervention study design. Given that all operations were performed by one surgeon, nevertheless some concerns could arise with regard to the consecutive nature of the cases and therefore possible differences in the outcome in favor of second group related to the gain of experience by the surgeon. However, we consider that the influence of this factor was minimal. The surgical experience of the operating urologist at the moment of the study embraced approximately 400 procedures, which exceed the average number of procedures to achieve the plateau on the learning curve, according to the recently published meta-analysis (25). Moreover, the number of procedures included in the study was not enormous to disclosure substantial experience-related differences. And also the observed substantial shift towards the better continence in the study group early after operation could be hardly explained only by virtual improvement in surgical experience.

\section{CONCLUSIONS}

The safety and efficacy of the new method of bladder neck reconstruction using a deep dorsal stitch was documented by this study. An 
improved early continence was proven, compared to the standard technique of bladder neck reconstruction using a "tennis racket". The possible explanation for this clinical effect could be the presence of proximal passive closure mechanism at the level of bladder neck, which probably promoted continence until the distal sphincter complex could take over.

\section{ABBREVIATIONS}

$\mathrm{BNR}=$ Bladder neck reconstruction

ICIQ-UI SF = International Consultation on Incontinence Questionnaire Urinary Incontinence Short Form

PSA $=$ Prostate-Specific Antigen

\section{CONFLICT OF INTEREST}

None declared.

\section{REFERENCES}

1. Ferlay J, Steliarova-Foucher E, Lortet-Tieulent J, Rosso $\mathrm{S}$, Coebergh JW, Comber $\mathrm{H}$, et al. Cancer incidence and mortality patterns in Europe: estimates for 40 countries in 2012. Eur J Cancer 2013;49:1374-403.

2. van Tol-Geerdink JJ, Willem Leer J, Weijerman PC, van Oort IM, Vergunst $H$, van Lin EN, et al. Choice between prostatectomy and radiotherapy when men are eligible for both: a randomized controlled trial of usual care vs decision aid. BJU Int. 2013;111:564-73.

3. Galvin DJ, Eastham JA. Critical appraisal of outcomes following open radical prostatectomy. Curr Opin Urol. 2009;19:297-302.

4. Prabhu V, Sivarajan G, Taksler GB, Laze J, Lepor H. Longterm continence outcomes in men undergoing radical prostatectomy for clinically localized prostate cancer. Eur Urol. 2014;65:52-7.

5. Jeong SJ, Kim HJ, Kim JH, Oh JJ, Lee SC, Jeong CW, et al. Urinary continence after radical prostatectomy: predictive factors of recovery after 1 year of surgery. Int $\mathrm{J}$ Urol. 2012;19:1091-8.

6. Kojima Y, Takahashi N, Haga N, Nomiya M, Yanagida T, Ishibashi K, et al. Urinary incontinence after robot-assisted radical prostatectomy: pathophysiology and intraoperative techniques to improve surgical outcome. Int $\mathrm{J}$ Urol. 2013;20:1052-63.
7. Cambio AJ, Evans C. Minimising postoperative incontinence following radical prostatectomy: considerations and evidence. Eur Urol. 2006;50:903-13.

8. Seaman EK, Benson MC. Improved continence with tubularized bladder neck reconstruction following radical retropubic prostatectomy. Urology 1996;47:532-5.

9. Poon M, Ruckle H, Bamshad BR, Tsai C, Webster R, Lui P. Radical retropubic prostatectomy: bladder neck preservation versus reconstruction. J Urol. 2000;163:1948.

10. Walsh PC, Marschke PL. Intussusception of the reconstructed bladder neck leads to earlier continence after radical prostatectomy. Urology 2002;59:934-8.

11. Lee DI, Wedmid A, Mendoza P, Sharma S, Walicki M, Hastings $\mathrm{R}$, et al. Bladder neck plication stitch: a novel technique during robot-assisted radical prostatectomy to improve recovery of urinary continence. J Endourol. 2011; 25:1873-7.

12. Connolly JA, Presti JC Jr, Carroll PR. Anterior bladder neck tube reconstruction at radical prostatectomy preserves functional urethral length--a comparative urodynamic study. Br J Urol. 1995;75:766-70.

13. Steiner MS, Burnett AL, Brooks JD, Brendler CB, Stutzman $\mathrm{RE}$, Carter HB. Tubularized neourethra following radical retropubic prostatectomy. J Urol. 1993;150:407-9.

14. Wille S, Varga $Z$, von Knobloch R, Hofmann R. Intussusception of bladder neck improves early continence after radical prostatectomy: results of a prospective trial. Urology 2005;65:524-7.

15. Sakai I, Harada K, Hara I, Eto H, Miyake H. Intussusception of the bladder neck does not promote early restoration to urinary continence after non-nerve-sparing radical retropubic prostatectomy. Int J Urol. 2005;12:275-9.

16. Rocco F, Luca Carmignani L, Acquati P, Gadda F, Dell'Orto P, Rocco B, et al. Early continence recovery after open radical prostatectomy with restoration of the posterior aspect of the rhabdosphincter. Eur Urol. 2007;52:376-83.

17. Shimizu T, Takahashi A, Ichihara K, Shinkai N, Ikeda T, Nojima $M$, et al. Anastomotic stricture following radical retropubic prostatectomy: insights into incidence, management and factors predisposing for occurrence. Nihon Hinyokika Gakkai Zasshi. 2012;103:604-9.

18. Wang R, Wood DP Jr, Hollenbeck BK, Li AY, He C, Montie JE, et al. Risk factors and quality of life for postprostatectomy vesicourethral anastomotic stenoses. Urology 2012;79:449-57.

19. Ouzaid I, Xylinas E, Ploussard G, Hoznek A, Vordos D, Abbou CC, et al. Anastomotic stricture after minimally invasive radical prostatectomy: what should be expected from the Van Velthoven single-knot running suture? J Endourol. 2012;26:1020-5. 
20. Paparel P, Akin O, Sandhu JS, Otero JR, Serio AM, Scardino PT, et al. Recovery of urinary continence after radical prostatectomy: association with urethral length and urethral fibrosis measured by preoperative and postoperative endorectal magnetic resonance imaging. Eur Urol. 2009;55:629-37.

21. Kordan Y, Alkibay T, Sozen S, Bozkurt Y, Acar C, Talu T, et al. Is there an impact of postoperative urethral and periurethral anatomical features in post-radical retropubic prostatectomy incontinence? Urol Int. 2007;78:208-13.

22. Karantanis E, Fynes M, Moore KH, Stanton SL. Comparison of the ICIQ-SF and 24 hour pad test with other measures for evaluating the severity of urodynamic stress incontinence. Int Urogynecol J Pelvic Floor Dysfunct. 2004;15:111-6.

23. Wein AJ. ICIQ: a brief and robust measure for evaluating the symptoms and impact of urinary incontinence. J Urol. 2005;173:908-9.
24. Hajebrahimi S, Corcos J, Lemieux MC. International consultation on incontinence questionnaire short form: comparison of physician versus patient completion and immediate and delayed self-administration. Urology 2004;63:1076-78.

25. Abboudi H, Khan MS, Guru KA, Froghi S, de Win G, Van Poppel $\mathrm{H}$, et al. Learning curves for urological procedures: a systematic review. BJU Int. 2014;114:617-29.

Correspondence address:

Yuri Tolkach, MD

Urology and Urologic Oncology Clinic

Carl-Neuberg-Str. 1 OE 6240

Hannover, 30625, Deutschland

Fax: +49 511532 163-449

E-mail: tolkach.iurii@mh-hannover.de 